\title{
Improving Hardenability of High Thickness Forged Steel Materials by Boron Addiction
}

\author{
Sabrina Mengaroni ${ }^{1}$, Paolo Emilio Di Nunzio ${ }^{1}$, Stefano Neri ${ }^{2}$, Massimo Calderini ${ }^{2}$ and Andrea Di Schino ${ }^{3 *}$ \\ 1. Centro Sviluppo Materiali SpA, Via di Castel Romano 100, 00128 Roma, Italy \\ 2. Acciai Speciali Terni, Viale Benedetto Brin 118, 05100 Terni, Italy \\ 3. Università degli Studi di Perugia, Dipartimento di Ingegneria, Via G. Duranti 93, 06125 Perugia, Italy
}

\begin{abstract}
To fulfill the industrial demand of forged steels with high mechanical and microstructural requirements coupled with reduced cost, the possibility to decrease the content of Mo and other elements has been evaluated. In order to do that, the effect of boron addition (up to $30 \mathrm{ppm}$ ) on the steel hardenability has been investigated on two steels with different chemical composition at laboratory scale. In particular, the steel chemical composition has been designed in order to make effective the B addition in terms of hardenability. Two $80 \mathrm{~kg}$ ingots cast by a vacuum induction melting plant have been hot rolled by a pilot mill. The effect of B addition on hardenability has been evaluated and compared to that of steel for same application but without B. Results show an improvement of hardenability if 30 ppm B are added even if a Mo reduction is performed.
\end{abstract}

Key words: Steels, Boron, hardenability.

\section{Nomenclature}

VIM: $\quad$ Vacuum induction melting

\section{Introduction}

Boron is usually added to steels in small concentrations to increase hardenability [1], especially in the case of high thickness components. The classical method of producing B-treated forged steels involves quenching and tempering treatment after forging. The optimization of the thermo-mechanical/quenching processing requires the addition of micro-alloying elements like Ti, Nb, V. At the same time, the formation of $\mathrm{Ti}$ and $\mathrm{Nb}$ nitrides and carbonitrides protects $\mathrm{B}$ against the formation of $\mathrm{BN}$ and $\mathrm{Fe}_{23}(\mathrm{C}, \mathrm{B})_{6}$. As a consequence, the segregation of $\mathrm{B}$ to the austenite grain boundaries is favored. This latter phenomenon is the generally accepted mechanism by which $B$ exerts a strong effect on hardenability [1-4]. Based on this mechanism it can be easily understood that B effect on hardenability will

\footnotetext{
*Corresponding author: Andrea Di Schino, Ph.D., professor, research field: metallurgy.
}

saturate at a value depending on austenite grain size. It is reported that the maximum B content exerting effect on hardenability for steels with austenite grain sizes ranging from 20 to $100 \mathrm{~m}$ is about $30 \mathrm{ppm}$. The combined addition of $\mathrm{B}$ and $\mathrm{Nb}$ to a Ti-protected carbon steel increases the tensile strength, which is mainly attributed to the suppression of $\mathrm{Fe}_{23}(\mathrm{C}, \mathrm{B})_{6}$ as a result of NbC precipitation [5]. This will also allow to reduce the presence of elements having effect on steel hardenability, typically expensive elements as Mo and $\mathrm{Ni}$. In this paper the possibility to reduce Mo and other expensive elements content has been evaluated in order to fulfill the industrial demand of forged steels.

\section{Experimental Setup}

A standard 40CrMnNiMo8-6-4 steel has been considered as a reference material. The main steel chemical composition according to UNI EN ISO 4957 for such steel is reported in Table 1.

Two $80 \mathrm{~kg}$ ingots have been cast at CSM VIM (Vacuum induction plant) with $\mathrm{B}$ addition. Ingots 
have been then hot rolled down to $40 \mathrm{~mm}$ in order to refine austenite grain size (thus favoring the effect of B). From hot rolled plates $10 \times 4 \mathrm{~mm}^{2}$ cylindrical specimens have been machined and dilatometric tests have been carried out by L78 RITA Linseis dilatometer after austenitisation at $\mathrm{T}=850 \mathrm{C} \times 600 \mathrm{~s}$. CCT (Continuous cooling transformation) plots have been built up and the results have been compared to those on a standard 40CrMnNiMo8-6-4 steel.

\section{Experimental Results}

\subsection{Steel Chemical Composition Design}

Taking as a reference the steel chemical composition reported in Table 2, calculations have been performed by means of JMatPro4 software, aimed to determine the Mo reduction allowed by 30 ppm $\mathrm{B}$ addition.

Results reported in Fig.1 show that hardenability behaviour is maintained if Mo is reduced from $0.22 \%$ down to $0.15 \%$ and 30 ppm B are added.

Based on these results, the chemical composition of Steel 2 is considered. It differs from that of Steel 1 mainly for Mo contents, kept at the lowest acceptable values for this class of materials (Table 3). In order to put in evidence the effect of $B$ on a steel with higher intrinsic hardenability, Steel 3, differing from Steel 2 mainly on $\mathrm{C}$ content, has been also considered.

In Table 4 the calculated minimum cooling rates for martensite $\left(\mathrm{v}_{\mathrm{crM}}\right)$, bainite $\left(\mathrm{v}_{\mathrm{crB}}\right)$ and ferrite/pearlite formation $\left(\mathrm{v}_{\mathrm{crP}}\right)$ are reported. They have been calculated according to a relationship of the form:

Table 1 Main steel chemical composition (wt\%) for 40CrMnNiMo8-6-4 (UNI EN ISO 4957)

\begin{tabular}{lllllll}
\hline & C $\%$ & Mn \% & Si \% & Cr \% & Mo \% & Ni \% \\
\hline Min. & 0.32 & 1.22 & 0.17 & 1.73 & 0.12 & 0.83 \\
Max. & 0.48 & 1.68 & 0.43 & 2.17 & 0.28 & 1.27 \\
\hline
\end{tabular}

Table 2 Reference steel chemical composition.

\begin{tabular}{llllll}
\hline & C \% & Mn \% & Cr \% & Mo \% & Other elements \\
\hline Steel 1 & 0.40 & 1.30 & 1.85 & 0.22 & Si, Ni \\
\hline
\end{tabular}

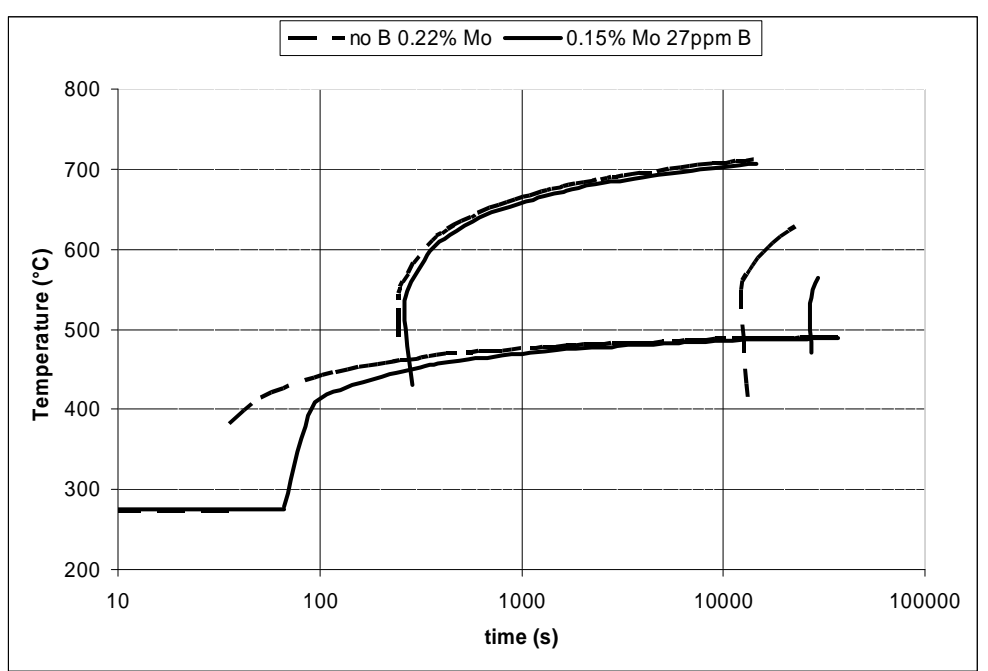

Fig. 1 Effect of B addition and Mo reduction on Steel 1 hardenability.

Table 3 Main steel chemical composition (wt, \%) for B added steels.

\begin{tabular}{llllll}
\hline & $\mathrm{C} \%$ & $\mathrm{Mn} \%$ & $\mathrm{Cr} \%$ & Mo \% & B ppm \\
\hline Steel 2 & $0.35-0.40$ & $1.40-1.60$ & $1.8-2.0$ & $0.15-0.20$ & 30 \\
Steel 3 & $0.45-0.50$ & $1.40-1.60$ & $1.8-2.0$ & $0.15-0.20$ & 30 \\
\hline
\end{tabular}




$$
\log _{10} \mathrm{v}_{\mathrm{Cr}}(\mathrm{i})=\mathrm{K}_{\mathrm{v}}(\mathrm{i})-\left(\mathrm{F}_{\mathrm{j}}(\mathrm{i}) \cdot \mathrm{wt} \%_{\mathrm{j}}+\mathrm{K}_{\mathrm{P}}(\mathrm{i}) \cdot \mathrm{P}_{\mathrm{a}}\right)
$$
where, $\mathrm{v}_{\mathrm{Cr}}(\mathrm{i})$ is the critical cooling rate in $\mathrm{K} / \mathrm{h}, \mathrm{K}_{\mathrm{V}}$, $\mathrm{K}_{\mathrm{P}}, \mathrm{F}_{\mathrm{j}}$ are coefficients reported in $[6,7]$ and the quantity $\mathrm{wt}_{\mathrm{j}} \mathrm{j}$ represents the weight percent of the element $\mathrm{j}$. It has to be mentioned that the above equation does not take into account the effect of $B$, thus such relationship should be considered as a guide to be experimentally verified.

Table 4 shows that in Steel 3, without B, martensite formation is favoured at higher cooling rates, while at low cooling rates the higher $\mathrm{C}$ content promotes the formation of pearlite.
In order to obtain an effective addition of $\mathrm{B}$ for improving the hardenability, the formation of boron nitrides must be avoided. This is usually accomplished by adding Ti which forms the more stable TiN. The amount of $\mathrm{Ti}$ needed to protect boron has been estimated by the MatCalc software (version 5.42) using the steel database mc_fe_v2.017.tdb. Calculations carried out on Steel 2 and Steel 3 show that, considering a typical nitrogen content of $60 \mathrm{ppm}$, at least 200 ppm Ti have to be added (Fig. 2). An increase of the $\mathrm{Ti}$ content does not improve the $\mathrm{B}$ protection.

Table 4 Critical cooling rates for Steels 2 and 3 (B not considered in calculation).

\begin{tabular}{llll}
\hline & $\begin{array}{l}\mathrm{V}_{\mathrm{crM}} \\
\left({ }^{\circ} \mathrm{C} / \mathrm{s}\right)\end{array}$ & $\begin{array}{l}\mathrm{V}_{\mathrm{crB}} \\
\left({ }^{\circ} \mathrm{C} / \mathrm{s}\right)\end{array}$ & $\begin{array}{l}\mathrm{V}_{\mathrm{crp}} \\
\left({ }^{\circ} \mathrm{C} / \mathrm{s}\right)\end{array}$ \\
\hline Steel 2 & 0.10 & 0.0006 & 0.14 \\
Steel 3 & 0.02 & 0.0002 & 0.01 \\
\hline
\end{tabular}
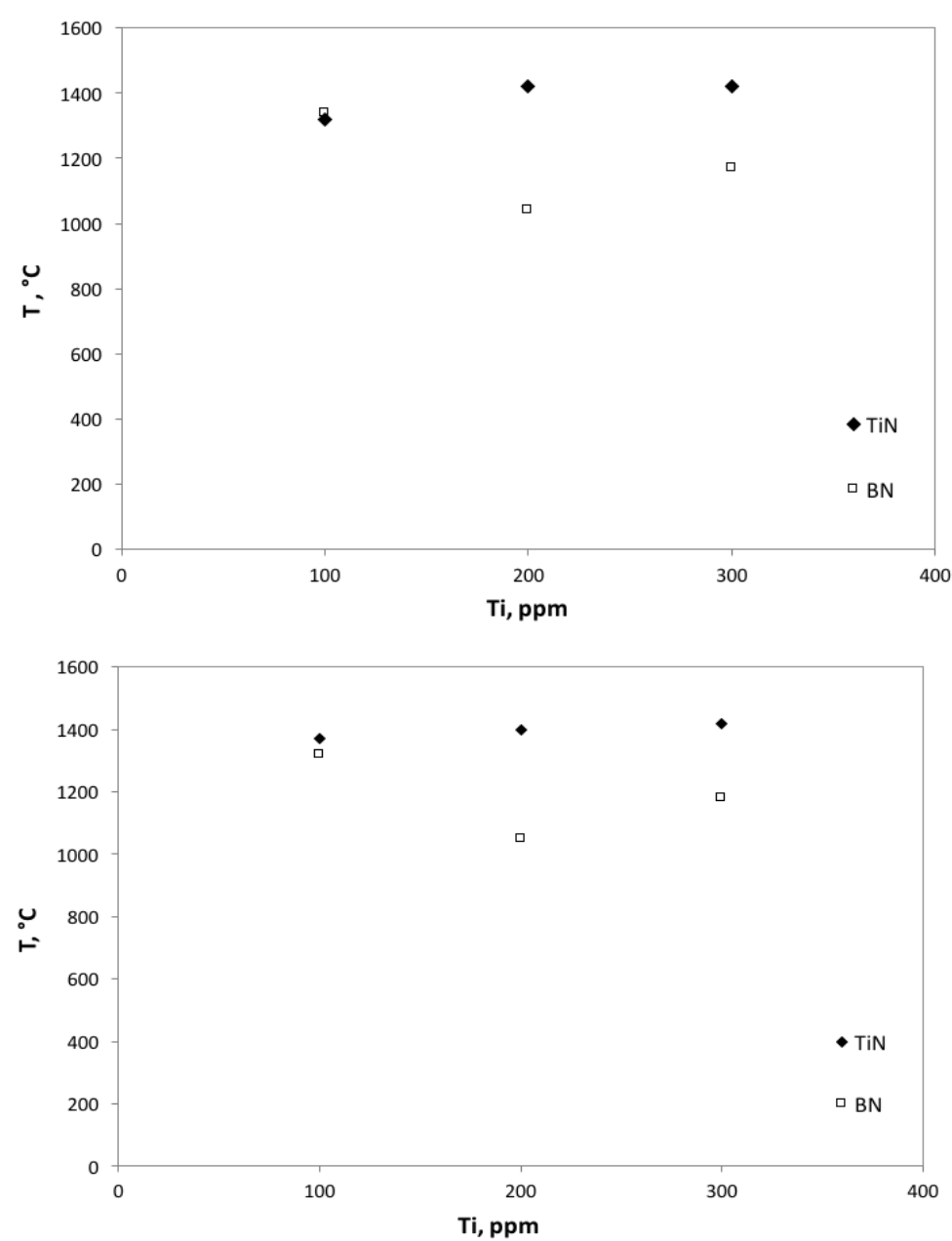

Fig. 2 Temperature of TiN and BN as a function of Ti content. 
Table 5 Main steel chemical composition (wt, \%) for $\mathrm{B}$ added steels $(\mathrm{N}=60 \mathrm{ppm}, \mathrm{Ti}=200 \mathrm{ppm})$.

\begin{tabular}{llllll}
\hline & $\mathrm{C} \%$ & $\mathrm{Mn} \%$ & $\mathrm{Si} \%$ & $\mathrm{Cr} \%$ & Mo, \% \\
\hline Steel 2 & 0.38 & 1.48 & 0.30 & 1.90 & 0.15 \\
Steel 3 & 0.48 & 1.58 & 0.30 & 2.00 & 0.17 \\
\hline
\end{tabular}

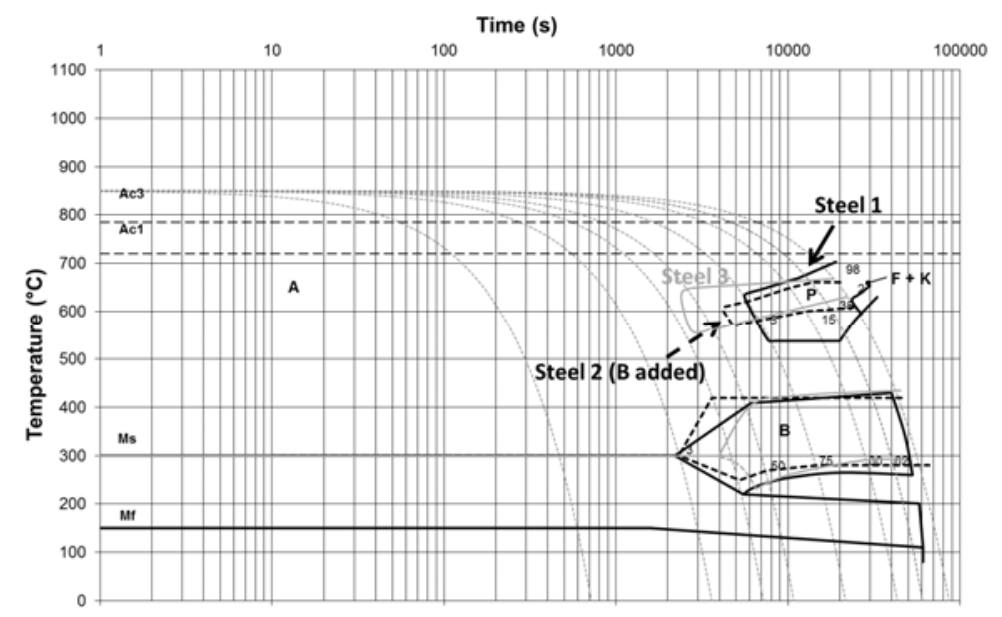

Fig. 3 Comparison of CCT curves.

Based on these considerations, the steels chemical composition reported in Table 5 have been cast and processed as reported in the experimental details.

\subsection{Hardenability}

Results from dilatometric tests show that the Mo and $\mathrm{Ni}$ reduction is well balanced in terms of hardenability by the addition of $30 \mathrm{ppm} \mathrm{B}$. In particular, a fully bainitic microstructure is achieved with a cooling rate down to $0.20 \mathrm{C} / \mathrm{s}$ and the pearlite formation is avoided down to $0.06 \mathrm{C} / \mathrm{s}$ (Figure 4). From a comparison of Steel 2 and Steel it appears that the higher C content in Steel 3 favors the martensitic transformation so that the bainite formation starts at lower cooling rates $(0.1 \mathrm{C} / \mathrm{s})$. On the other hand, a higher $\mathrm{C}$ content also favors the formation of pearlite $(\mathrm{CR}<0.15 \mathrm{C} / \mathrm{s})$. As expected, the effect of carbon in increasing the hardenability is present also after the addition of boron.

\section{Conclusions}

The addition of $30 \mathrm{ppm}$ B to a 40CrMnNiMo8-6-4 steel with $0.38 \%$ C permits a reduction of Mo from $0.22 \%$ down to $0.15 \%$ while maintaining the intrinsic hardenability and considerably reducing the production costs. To exploit the effect of $\mathrm{B}$ on hardenability, a proper addition of $\mathrm{Ti}$ is required in order to prevent the formation of BN. The increase of C content up to $0.50 \%$ favors martensite formation at higher cooling rates, but also promotes the pearlite formation at lower cooling rates.

On the industrial scale, since lower cooling rates are typical of the central regions of large-thickness components, the results here obtained suggest that an increase of $\mathrm{C}$ to further improve hardenability is not suitable.

\section{References}

[1] Llewellyn, D. T. 1993. "Boron in Steels.” Ironmaking \& Steelmaking 20: 338-43.

[2] Taylor, K. A. 1992. "Grain-Boundary Segregation and Precipitation of Boron in. 0.2 Percent Carbon Steels.” Metall. Trans. A 23A: 107-19.

[3] Shigesato, G., Fujishiro, T. and Hara, T. 2014. "Grain Boundary Segregation Behavior of Boron in Low-Alloy Steel.” Metall. Mater. Trans. A 45A: 1876-82.

[4] Li, Y. J., Ponge, D., Choi, P. and Raabe, D. 2015. "Segregation of Boron at Prior Austenite Grain Boundaries in a Quenched Martensitic Steel Studied by Atom Probe Tomography.” Scripta Mater. 96: 13-6.

[5] Hara, T., Asahi, H., Uemori, R. and Tamehiro, H. 2004. 
"Role of Combined Addition of Niobium and Boron and of Molybdenum and Boron on Hardenability in Low Carbon Steels.” ISIJ Inter. 44: 1431-40.

[6] Maynier, P., Dollet, J. and Bastien, P. 1970. "The influence of Alloying Elements on the Quench Characteristics of
Low-Alloy Steels.” Rev. Mét. 67: 343-51.

[7] Maynier, Ph., Dollet, J. and Bastien, P. 1978. Hardenability Concepts with Application to Steel. Ed. by Doane, D. V. and Kirkaldy, J. S. TMS-AIME, Warrendale, PA, 163-8. 